\title{
Cryogenic and Cryostat System for the 56 MHZ SRF Cavity
}

\author{
R. Than
}

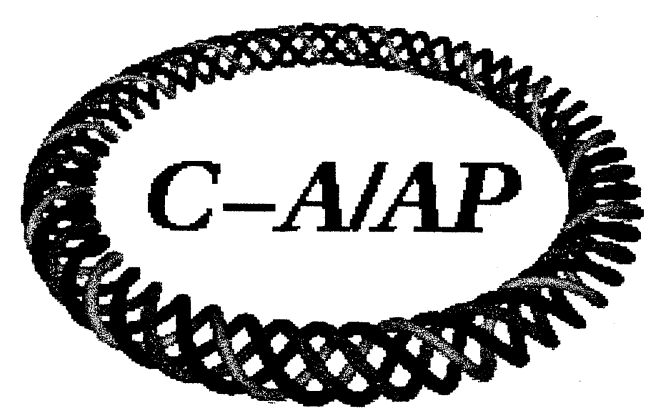

\section{Collider-Accelerator Department Brookhaven National Laboratory \\ Upton, NY 11973}

Notice: This document has been authorized by employees of Brookhaven Science Associates, LLC under Contract No. DE-AC02-98CH10886 with the U.S. Department of Energy. The United States Government retains a nonexclusive, paid-up, irrevocable, world-wide license to publish or reproduce the published form of this document, or allow others to do so, for United States Government purposes. 


\title{
BROOKHAYEN
}

NATIONAL LABORATORY

\section{CRYOGENIC AND CRYOSTAT SYSTEM \\ FOR THE 56 MHZ SRF CAVITY}

\author{
Cryogenics Systems Group \\ Collider Accelerator Department \\ R. Than
}




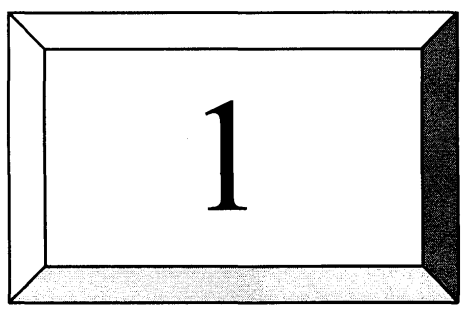

\section{SYSTEM CONFIGURATION}

\subsection{Configuration}

\section{System Level Configuration (Figure 1)}

Liquid helium is taken from RHIC's main helium headers to supply liquid helium to the cavity system. Because of the low design pressure of 20 psia ( $\sim 5 \mathrm{psig})$ and pressure stability concerns for the cavity, the boil-off cannot return to the RHIC's main cold vapor return line (R-Line), which would provide the most efficient operating configuration. Instead, the boil-off vapor is return to a small local compressor that will re-inject the helium back to the main warm return header to the main cryo plant. A refrigeration recovery heat exchanger system can be implemented, to decrease the load on the cryo plant by converting the liquefaction load to a refrigeration load. The refrigeration recovery high pressure cold gas is returned to RHIC's cold vapor return header. The transfer line heat load from the RHIC main to the cryostat is removed in a separate phase separator (\#1) and this vapor is return back to RHIC main cold vapor return.

\section{Liquid Helium Supply}

Liquid helium can be taken from two of RHIC's main cryogen headers, the S or M headers. Although liquid helium supply from the $\mathrm{M}$ header is more stable in temperature than the $\mathrm{S}$-header, tie-in with the $\mathrm{S}$ header is a lower risk task than tie-in with the $\mathrm{M}$-header because of the superconducting bus running through the M-header.

Because of mechanical and flow induced pulses in the liquid helium supply, the supply pressure in RHIC's main headers exhibits variation of approximately $0.75 \mathrm{psi}$ at several frequencies below $20 \mathrm{~Hz}$.

\section{Transfer Line System}

A $1 / 2$ " line tap from the S-header (main supply header to RHIC recoolers) will supply helium to the cryostat system and the a 1 " cold vapor return line will take vapor from the $1^{\text {st }}$ separator and recovery coldbox back into the $\mathrm{R}$ header, RHIC main cold vapor return header.

\section{Cryostat System (Figure 2)}

\section{First Separator (\#1)}

The system consists of a first separator that takes the 3.5 - $4 \mathrm{~atm}, 4.6 \mathrm{~K}$ RHIC liquid helium and flashes it down to $1.5 \mathrm{~atm}$ or a pressure sufficient to provide a reasonable pressure drop through the thermal transition intercepts. The vapor from the first separator is returned to RHIC's cold vapor return header, the R-header. The $1^{\text {st }}$ separator serves to isolate the pressure pulses from the RHIC's liquid supply lines, and is where the heat load from the transfer lines is removed. Liquid from the $1^{\text {st }}$ separator supplies the condenser loop's separator (\#2) and also the flow to the heat intercepts on the thermal transition pieces, and fundamental damper wall.

\section{Condenser/Boiler Loop (Separator \#2 and Condenser)}

The condenser heat exchanger is located in the cavity-cryostat's upper reservoir. Cooling is provided by a boiling/siphon loop on one side of the heat exchanger, that recycles to separator \#2. Boil-off from this separator is returned to the local compressor via the recovery heat exchanger. The boiling point in separator \#2 is set by the local recovery compressor suction pressure, which has to operate low enough to keep the condensing pressure in the cavity's helium space below the maximum allowable working pressure. 
COLLIDER ACCELERATOR DEPARTMENT

Project: $56 \mathrm{MHz}$ SCRF Cavity

Title: Cryogenic and Cryostat System for the $56 \mathrm{MHz}$ Cavity

\section{Cavity Cryostat and Condenser space/Liquid Reservoir}

The cavity is enclosed in a Titanium vessel that carries the liquid helium bath that cools the cavity. It is connected to a holdup vessel that will contain a condenser/boiler heat exchanger

\section{Beam tube ends thermal transition heat intercept}

Both beam tube transitions to the warm bore will have a heat intercept using $1.5 \mathrm{~atm}, 4.6 \mathrm{~K}$ helium from separator \#1. A flow of $0.05 \mathrm{~g} / \mathrm{s}$ is budgeted, for a heat intercept of $20 \mathrm{~W}$ from $4.6 \mathrm{~K}$ to $\sim 80 \mathrm{~K}$. The exit helium will be used to cool the thermal shield. This flow is returned to RHIC main warm return header located in the tunnel.

\section{Fundamental damper thermal transition heat intercept}

The fundamental damper walls will have a heat intercept using $1.5 \mathrm{~atm}, 4.6 \mathrm{~K}$ helium from separator \#1. A flow of $0.075 \mathrm{~g} / \mathrm{s}$ is budgeted, for a heat intercept of $30 \mathrm{~W}$ from $4.6 \mathrm{~K}$ to $\sim 80 \mathrm{~K}$. The exit helium flow is returned to RHIC main warm return header located in the tunnel.

\section{Thermal Shield}

The thermal shield is cooled by the two exit gas streams of the beam-tube thermal transitions.

The thermal shield helium gas is returned to RHIC's main warm return header located in the tunnel.

An outer MLI system will be mounted on the vacuum vessel wall to reduce the heat load on the thermal shield.

\section{Liquid Fill Line for portable dewar fill}

A bayonet connection is provided into separator $\# 2$ to allow cold tests while the RHIC cryoplant is shutdown.

\subsection{System Heat Loads}

\begin{tabular}{|c|c|c|c|c|c|}
\hline Item & $\begin{array}{c}\text { Load } \\
@ 4.45 \mathrm{~K}\end{array}$ & Flow & $\begin{array}{l}\text { RHIC Main Cryo } \\
\text { Plant } \\
\text { Refrigeration } \\
\text { Load } \\
\end{array}$ & $\begin{array}{l}\text { RHIC Main Cryo } \\
\text { Plant } \\
\text { Liquefaction } \\
\text { Load } \\
\end{array}$ & $\begin{array}{l}\text { RHIC Main Cryo } \\
\text { Compressor Power } \\
\text { (@20\%Carnot) }\end{array}$ \\
\hline & W & $g / s$ & W & $\mathrm{g} / \mathrm{s}$ & MW \\
\hline Separator 1 & 40 & & 40 & & 0.015 \\
\hline $\begin{array}{c}\text { Cavity } \\
\text { Cryostat + } \\
\text { Hold up Volume / Condenser } \\
\text { Cryostat/Separator\#2 } \\
\end{array}$ & 100 & & & 5.7 & 0.199 \\
\hline $\begin{array}{c}\text { Beam tube Thermal transition } \\
\text { Intercepts plus flow to shield } \\
\text { in series }\end{array}$ & & $2 \times 0.05$ & & 0.1 & 0.0036 \\
\hline $\begin{array}{c}\text { Fundamental Damper } \\
\text { Thermal Intercept }\end{array}$ & & 0.075 & & 0.075 & 0.0028 \\
\hline TOTAL & & & & 5.875 & 0.22 \\
\hline
\end{tabular}




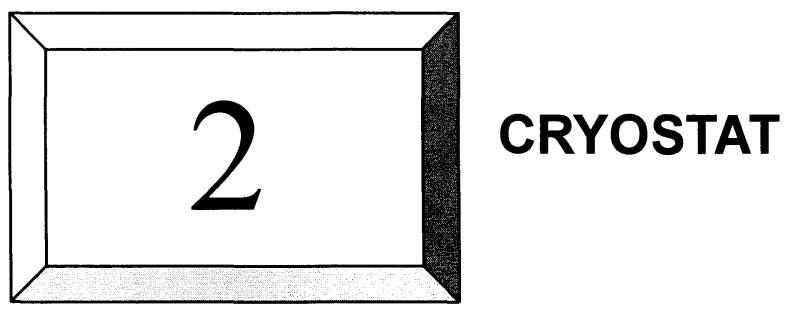

\subsection{Cavity Cooling}

The preferred method is to cool the cavity in a helium bath (nucleate pool boiling). Because of the tight pressure variation requirements on the helium bath, and the vibration pulses from RHIC's main cryogenic lines, a condenser/boiler system is proposed to recondense the vapor generated within the cavity's cryostat system vapor space.

\section{Heat Flux Density}

The total heat dissipation due to losses on the Niobium surface is estimated at $42 \mathrm{~W}$. With peak dissipation densities at the damper end of the cavity. Maximum heat flux density is $40 \mathrm{~W} / \mathrm{m}^{2}$. This means that for most of the surface cavity surface the heat flux will be in the free convection regime or the surface will superheat approximately $50 \mathrm{mK}$ above the saturation temperature before nucleate boiling will occur. It is

\section{Vapor trapping on inner annular volume}

Because of the geometry of the cavity, the inner annular space of the cavity will trap vapor that is generated from the boiling process on the high point on the inner annulus of the niobium surface. This is believe not pose a problem, but a simple experiment in a small dewar has been setup to determine whether the trapped vapor will lead to any excessive temperatures at the high point of the curved niobium surface.

\section{Conduction cooling of Cavity}

Some parts of the cavity, such as the tuning surface will conduction cooled. The heat dissipation flux is low enough to allow conduction cooling to the edge of the tuner plate, and still keep the tuner surface temperature below

\subsection{Liquid Helium Supply Pressure Pulses and Mechanical Vibrations}

\section{Helium supply from RHICs}

Due to the tuning requirements of the cavity, every effort is made to eliminate, minimize, dampen, or isolate sources of mechanical vibration or variation in pressure in the cavity's helium reservoir, piping, and support system. A condenser/boiler system is proposed to recondense the vapor generated by the cavity heat load, to isolate the cavity helium space from the helium supply/return of the cryogenic system and plant.

\section{Piping $1^{\text {st }}$ Modes}

Piping connected to the cavity reservoirs will be engineered to have sufficient stiffness to obtain $1^{\text {st }}$ modes with frequencies greater than $100 \mathrm{~Hz}$.

\section{TAO}

To mitigate any Thermal Acoustic Oscillations, TAO, no small diameter tubing shall be used that will extend to warm region outside the vacuum boundary. Small diameter relief lines shall have a check valve at the cold end of the line, and any instrumentation tubing for pressure sensors shall have a 5 turn cold end stabilization loop in the tubing. Stability analysis shall be done on other tubing connected to a warm environment. 
COLLIDER ACCELERATOR DEPARTMENT

Project: $56 \mathrm{MHz}$ SCRF Cavity

Title: Cryogenic and Cryostat System for the $56 \mathrm{MHz}$ Cavity
Rev: Design Review Jan 09

\section{Pool boiling Noise}

In general, noise from boiling helium has a broad frequency spectrum and sufficiently low enough amplitude to not be an issue.

\subsection{Heat Load Breakdown}

HELIUM LOAD 1: Returns back to RHIC Vapor Return Header: $20+9.3=29.3$. Budget: $40 \mathrm{~W}$

This load includes the transfer lines loads and the $1^{\text {st }}$ phase separator that isolates the Collider supply transients from the cavity system. The boil from this phase separator is returned to the Collider's main cold vapor return line.

Cold transfer line system from/to RHIC main cryogenic lines: $15 \mathrm{~W}$

Phase separator \#1 Loop: $9.3 \mathrm{~W}$
Supports: $2 \mathrm{~W}$
Helium Vessel, unshielded: $2 \mathrm{~W}$
2 Valves: $3 \mathrm{~W}$
Helium Lines: $1 \mathrm{~W}$
Instrument lines: $0.3 \mathrm{~W}$ Relief line: $1 \mathrm{~W}$

HELIUM LOAD 2: Returns back to Cavity Cryostat's Refrigeration Recovery Compressor:

$\mathrm{Q}=74.8 \mathrm{~W}$. Budget: 100W

( $\sim 5 \mathrm{~g} / \mathrm{s}$ liquefaction load on RHIC Plant without recovery)

Separator \#2 and Condenser / Hold-up Vessel (Separator\#3): $18.3 \mathrm{~W}$

Helium Holdup vessel Radiant Load, shielded: $2 \mathrm{~W}$

Supports: $2 \mathrm{~W} \quad$ Helium Lines: $1 \mathrm{~W}$

4 Valves: $8 \mathrm{~W} \quad$ Instrument lines: $0.3 \mathrm{~W}$

Relief line: $5 \mathrm{~W}$

Cavity Cryostat: $14.5+42=56.5 \mathrm{~W}$

Helium vessel Radiant Load, shielded: $2 \mathrm{~W}$

Beam tube end with intercept (Damper end): $3 \mathrm{~W}$

Besides the conductive load, the thermal radiation the load is minimized by having a low emissivity surface thermal transition material. In order to reflect the warm bore radiation properly, the surface has to behave as a diffuse reflecting surface, not a specular reflecting surface.

Beam tube end with intercept (Tuner end): $3 \mathrm{~W}$

Supports: $2 \mathrm{~W}$

Tuner: $2 \mathrm{~W}$

Fundamental Damper: 2W Power coupler: $0.5 \mathrm{~W}$

Maximum Dynamic: $42 \mathrm{~W}$

\section{HEAT STATION LOADS}

Fundamental Damper Heat intercept station flow: $0.075 \mathrm{~g} / \mathrm{s}$

Beam Tube End (tuner side): heat intercept station and cryostat radiation shield: $0.05 \mathrm{~g} / \mathrm{s}$. 
COLLIDER ACCELERATOR DEPARTMENT

Project: $56 \mathrm{MHz}$ SCRF Cavity

Title: Cryogenic and Cryostat System for the $56 \mathrm{MHz}$ Cavity

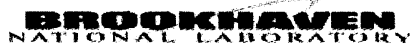

Rev: Design Review Jan 09

\subsection{Equipment SEPARATOR \#1}

Vessel size, vapor space, and separation requirements are set by larger of:

a. Separation requirement due to Heat load on the separator loop which includes transfer line heat leak

b. Hold up time requirements

c. Vapor space required to dampen liquid/vapor fluctuations from the supply

a. Maximum saturation condition to $1.65 \mathrm{~atm} .4 .8 \mathrm{~K}$

Liquid density: $110.1 \mathrm{~kg} / \mathrm{m}^{3}$. Vapor Density: $30.4 \mathrm{~kg} / \mathrm{m}^{3}$

Vapor mass flow steady state nominal: $2 \mathrm{~g} / \mathrm{s}$

Vapor mass flow peak: $6 \mathrm{~g} / \mathrm{s}$

Minimum required diameter for separation: 12 inch

b. Holdup requirements

Hold up time: 20 min

Hold up Liquid requirement: 12000 grams

Hold up liquid volume required: 100 liters

c. Vapor space required to dampen liquid/vapor fluctuations from the supply

For $1 \mathrm{psi}(69 \mathrm{mbar})$ low frequency ( $10 \mathrm{~Hz}$ and lower) variation in liquid supply pressure (3.5 atm supply), there will be a corresponding variation the flowrate into the separator, through the supply control valve. For a maximum $10 \mathrm{~g} / \mathrm{s}$ supply and a flow variation of $2 \%$, for pulses under $10 \mathrm{~Hz}, 100$ liters vapor space would provide a pressure change of order 1 mbar in separator \#1.

Design size: 22 in Dia. $x 36$ in $\mathrm{H}$.

\section{SEPARATOR \#2}

Separator \#2, which handles the heat load from the cavity/holdup volume reservoir via the condenser/boiler heat exchanger. It receives the boil-off and supplies the liquid to the boiler/condenser heat exchanger located in the cryostat holdup volume. Liquid is supplied to this separator from Separator \#1.

Separator minimum diameter is set by total heat load duty.

a. Maximum saturation condition to $1.3 \mathrm{~atm} .4 .5 \mathrm{~K}$

Liquid density: $118.1 \mathrm{~kg} / \mathrm{m}^{3}$. Vapor Density: $22.4 \mathrm{~kg} / \mathrm{m}^{3}$

Vapor mass flow steady state nominal: $6 \mathrm{~g} / \mathrm{s}$

Vapor mass flow peak: $6 \mathrm{~g} / \mathrm{s}$

Minimum required diameter for separation: 12 inch

b. Holdup requirements

Hold up time: 20 min

Hold up Liquid requirement: 7200 grams

Hold up liquid volume required: 60 liters

Design size: 22 in Dia. $x 36$ in $\mathrm{H}$. 


\section{SEPARATOR \#3 Cavity Hold-up vessel}

Response of pressure transients caused from thermal transients by the cavity's change in dynamic dissipation load will be dictated by the size of the vapor space, the condenser response. Using 1000 liter vessel with 500 liter vapor space, the vapor phase inventory is about $10 \mathrm{~kg}$.

Fast Transients: With a 0.1 mbar variation will handle a dynamic variation in the load of $\sim 20$ Joules.

Slow transients: For load changes over long time span, the condensing/boiler and vapor inventory system will react to this with a shift in operating state point.

For a load increase of $40 \mathrm{~W}$, heat transfer gradient will increase approximately $50 \mathrm{mK}$, with a vapor pressure slope $\mathrm{dT} / \mathrm{dP} \sim 1 \mathrm{mK} / \mathrm{mbar}$, the increase in vapor pressure on the cavity will cause of shift of 50 mbar $\mathrm{x} \sim 0.3 \mathrm{~Hz} / \mathrm{mbar} \sim 15 \mathrm{~Hz}$.

Liquid level head effects

With liquid densities of around $120 \mathrm{~g} / \mathrm{L}$, a $1 \mathrm{~cm}$ change in liquid will change the pressure above the cavity by 0.12 mbar

Design size: 36 in Dia. $x 60$ in $\mathrm{H}$

\section{Condenser/Boiler Heat Exchanger}

Condenser side

Condensing heat transfer film coefficients remain constant at around $600 \mathrm{~W} / \mathrm{m}^{2}-\mathrm{K}$.

For a condensing temperature gradient of $25 \mathrm{mK}$ and $100 \mathrm{~W}$ load, a condensing surface area of $6.6 \mathrm{~m}^{2}$ is required.

\section{Boiler Side}

A siphon loop will be setup between the boiler side of the heat exchanger and the separator vessel. If a finned copper tube design is used, with a nominal tube area to fin area ratio of $1: 6$, a nucleate boiling temperature gradient of approximately $55 \mathrm{mK}$ will be established. The boiling side heat transfer gradient can be improved if the surface roughness on the tube side can be increased to increase nucleation and therefore the heat transfer coefficient.

A brazed aluminum plate-fin heat exchanger option will be investigated also, since these have been in used as sub-cooler heat exchangers in liquid helium reservoir.

Duty: $85 \mathrm{~W}$

$\mathrm{UA}: 773 \mathrm{~W} / \mathrm{K}$

Surface Area Condensing Side: $6.6 \mathrm{~m}^{2}$

Surface Area Boiler Side: $1.1 \mathrm{~m}^{2}$

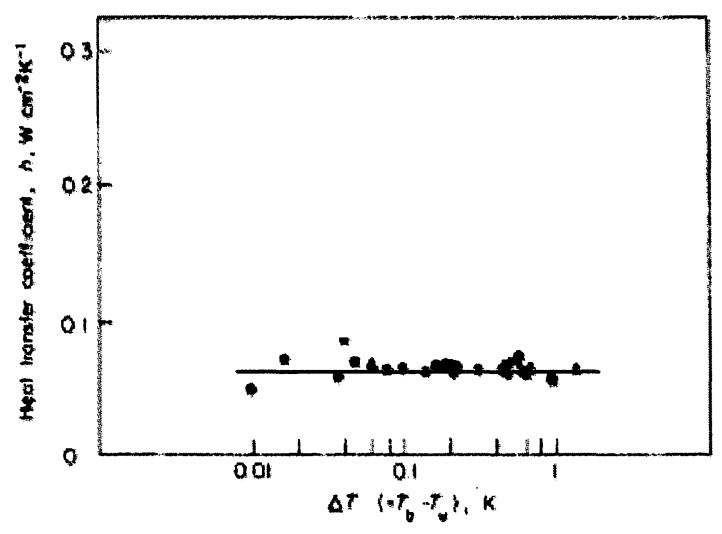

Condensing Heat Transfer Coefficient 


\subsection{Cooldown}

A cooldown line is provided to supply helium from the first separator to a lower port on the cavity for cooldown. Analysis to study cooldown temperature gradients and stresses still needs to be carried out. Cooldown from room temperature to $150 \mathrm{~K}$ can be carried out at a slower pace, and accelerated below $150 \mathrm{~K}$ to transition through the Q-disease regime quickly.

\subsection{Warmup}

To provide reasonable warm-up time, heaters can be installed on the Titanium helium vessel. A purge line into separator \#2 is provided for purging and warm-up. Gas can enter the cavity via the cooldown valve and warm the cavity.

\subsection{Reliefs}

\begin{tabular}{|l|l|l|l|l|}
\hline & Separator \#1 & $\begin{array}{l}\text { Separator \#2/ } \\
\text { Condenser- } \\
\text { Boiler }\end{array}$ & $\begin{array}{l}\text { Cavity helium } \\
\text { volume \& } \\
\text { Condensing space } \\
\text { / Hold-up tank } \\
\text { (Separator \#3) }\end{array}$ & $\begin{array}{l}\text { UHV } \\
\text { BEAM TUBE } \\
\text { Reliefs }\end{array}$ \\
\hline MAWP Pressure & 275 psia & $100 \mathrm{psig}$ & 20 psia & \\
\hline Normal Operating & $25 \mathrm{psia}$ & $16.2 \mathrm{psia}$ & $17.7 \mathrm{psia}$ & \\
\hline Relief-1 SP & $250 \mathrm{psig}$ & $100 \mathrm{psig}$ & $5 \mathrm{psig}(20 \mathrm{psia})$ & $6 \mathrm{psig}$ \\
\hline Relief-2 SP & & & $8 \mathrm{psig}(23 \mathrm{psia})$ & \\
\hline Criteria -1 & $\begin{array}{l}\text { Loss of insulating } \\
\text { vacuum to air }\end{array}$ & $\begin{array}{l}\text { Loss of insulating } \\
\text { vacuum to air }\end{array}$ & Cooldown flow & $\begin{array}{l}\text { Cavity breach, } \\
\text { helium into UHV }\end{array}$ \\
\hline Flow-1 & TBD & TBD & 25 g/s & TBD \\
\hline Criteria -2 & & & $\begin{array}{l}\text { Loss of UHV beam } \\
\text { vacuum to air }\end{array}$ & \\
\hline Flow-2 & & & $2500 \mathrm{~g} / \mathrm{s}$ & \\
\hline
\end{tabular}


COLLIDER ACCELERATOR DEPARTMENT

Project: $56 \mathrm{MHz}$ SCRF Cavity

Title: Cryogenic and Cryostat System for the $56 \mathrm{MHz}$ Cavity

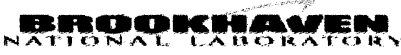

Rev: Design Review Jan 09

\subsection{Process Data, Nominal Steady State}

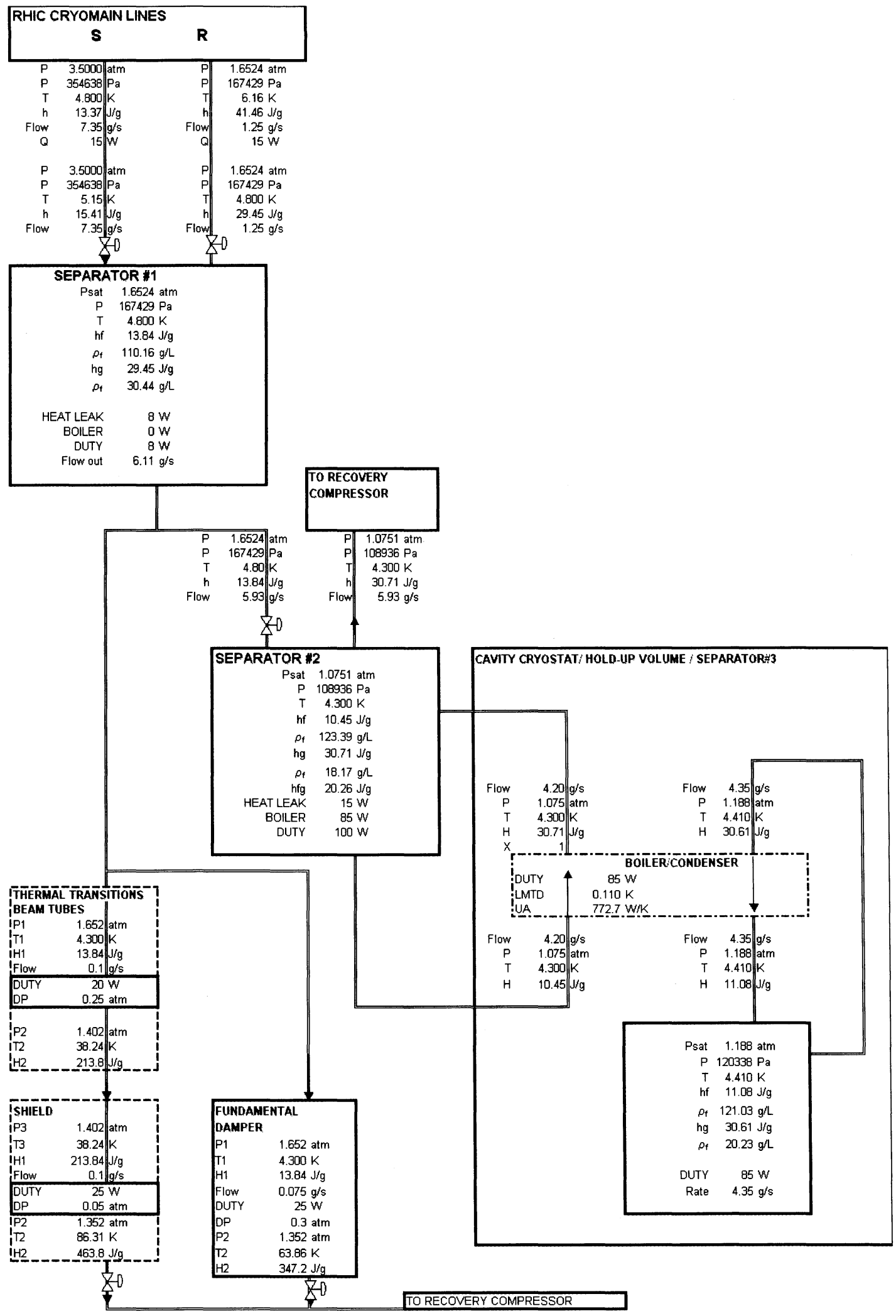


COLLIDER ACCELERATOR DEPARTMENT

Project: $56 \mathrm{MHz}$ SCRF Cavity

Title: Cryogenic and Cryostat System for the $56 \mathrm{MHz}$ Cavity

10

\section{References}

Sato, S, and Ogata, H. "Film condensation heat transfer of helium in a vertical tube". Cryogenics, April 1976.

Van Sciver, S. W., “ Helium Cryogenics”, Plenum Press, New York, 1986.

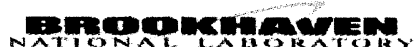

Rev: Design Review Jan 09 